show in what way the proposed novelty can be of any use whatever. It is claimed that the " report should prove to be a convenient work of reference in the brickmaking and refractory-using industries." This claim will be abundantly justified ; the Geological Survey is to be congratulated on the utility of these Special Reports.

J. W. Mellor.

The Pharmacists' Botany. By Dr. George B. Rigg. Pp. xvii +303. (New York: The Macmillan Company, r924.) I6s. net.

MANY of the drugs in common use as medicines are derived from the vegetable kingdom, and are to a great extent supplied to the public by the pharmacist, who has to guarantee their identity and freedom from adulteration. For this reason the pharmacist is required to undergo an adequate training in the science of botany, for which a number of excellent text-books have been published, and institutes exist in which lectures and instruction in practical work are available. Indeed, so large is the number of text-books that it is difficult to understand the necessity for an additional one unless it presents the subject in a manner specially adapted for a particular class of students. Prof. Rigg says that his aim has been " to include not only those phases of botany that are of specific use to the pharmacist, but also to give a general view of the subject which will serve as a background for him in his professional work."

A knowledge of the morphology and anatomy of the parts of plants used in medicine is particularly essential to the pharmacist, and in these respects a pharmacists' botany should give fairly complete, accurate, and precise information. Prof. Rigg's book does not satisfy this condition; and inaccurate statements occur so frequently as to constitute a serious blemish. The book is well printed, and is illustrated by a number of photographs which, for the most part, answer the purpose for which they are employed. It cannot, however, be recommended for pharmaceutical students or pharmacists until it has been thoroughly revised, erroneous statements corrected, and the details more systematically arranged.

Penrose's Annual: the Process Year Book and Review of the Graphic Arts. Edited by Wm. Gamble. Vol. 27. Pp. $\mathrm{xv}+\mathrm{I}_{42}+60+80$ plates. (London: Percy Lund, Humphries and Co., Ltd., r925.) 8s. net.

Although, as stated in the review of process work, there has been no outstanding achievement during the past year, the editor has provided a very pleasing and useful volume, as his custom is. The making of halftone blocks seems to have arrived at a degree of perfection that it is very difficult even if possible to surpass, though the method may perhaps be simplified by the efforts made to render it more systematic. Rotary photogravure is being applied to multicolour printing, and the method is being successfully worked on sheetfed machines producing excellent work up to speeds of 2500 copies per hour for each colour. A higher output may be expected from the same cylinders when rotary web machines are available. The replacement of the costly solid or tubular copper cylinders used for rotary gravure by iron cylinders faced with thin copper sheets has considerably advanced during the year.
The type used for the letterpress of the volume appears to be a modern reproduction of the Aldine type of the Hypnerotomachia Poliphili issued in I499, concerning which there is an introductory article. The private press dealt with in an illustrated article is this year the Daniel Press owned by the late Rev. C. H. O. Daniel, of Oxford. Among the very numerous illustrations is a series of examples of posters, mostly in colours, twenty-four reproductions of the celebrated woodcuts of the 'sixties, many examples of offset printing and of colour work, all of which are excellent and of considerable technical interest, and some admirable also because of the beauty of the originals.

A Bibliography of Printed Maori to 19oo. By Dr. H. W. Williams. (Dominion Museum Monograph, No. 7.) Pp. xvi + r98. (Wellington, N.Z.: W. A.G. Skinner, I924.) n.p.

DR. WrrLiams' bibliography of printed Maori publications contains nearly I roo items. The mere number, however, does not nearly represent the amount of labour which has been expended in its compilation, as each entry is annotated with information additional to the formal particulars, and in many cases some indication is given of the character of the contents. The author has departed from the strict rule followed by many bibliographers and has included items which he has not personally examined, but as such entries are indicated, those who use the bibliography will in these cases be on their guard. The entries are in chronological order - a disadvantage if the date of the book about which information is sought is not known, or if it is undated -but as the entries are naturally of a very miscellaneous character, ranging from Bibles and prayers to newspapers, dictionaries, and government documents, any satisfactory classification would be a matter of extreme difficulty. Further, the deficiency is to some extent made good by a very full index and a list of authors and translators. In the preface, Dr. Williams reviews previous attempts at Maori bibliography, and his introduction is a valuable account of Maori presses in which the work of the various missionary societies, both in reducing Maori to a written language and in printing it, is fully recognised. The first book to be printed in the language was "The New Zealander's First Book," by Thomas Kendall, the missionary (18I5), for the instruction of the natives. It is, Mr. Williams says, scarcely to be recognised as Maori at all.

\section{An Introduction to the Mathematical Analysis of} Statistics. By Prof. C. H. Forsyth. Pp. viii +24I (New York: J. Wiley and Sons, Inc.; London: Chapman and Hall, Ltd., I924.) IIs. 6 d. net.

ThIs work is intended primarily as a text-book for a course in mathematics and not as a reference book for the statistician. It is to be doubted, however, whether the mathematician as such will be quite satisfied with it. In its scope it is modest, commencing with useful chapters on numerical computation, finite differences, and interpolation, and proceeding by easy stages. through probability, averages, a treatment of the normal frequency curve, to correlation. While there are copious and useful examples, the mathematical treatment is patchy and uneven; it is a useful interesting, but unsatisfying production. 